\title{
Shoot Biomass Assessments of the Marine Phanerogam Zostera marina for Two Methods of Data Gathering
}

\author{
Elena Solana-Arellano*, Héctor Echavarría-Heras, Victoria Díaz-Castañeda, Olga Flores-Uzeta
}

Marine Ecology Department, Ensenada Scientific and Higher Education Center, Baja California, México.

Email: *esolana@cicese.mx

Received August $8^{\text {th }}, 2012$; revised September $16^{\text {th }}, 2012$; accepted October $10^{\text {th }}, 2012$

\begin{abstract}
In order to compare to data gathering methods for shoot biomass assessments of Zostera marina, we compare two allometric models each one representing a data gathering method, one at leaf level and the other in aggregated form. The first allometric model presented leaf dry weight in terms of leaf length as $w=\beta l^{\alpha}$. The second model is expressed as a several-variables version of the allometric Equation (1) dry weight of each leaf in a given shoot can be considered to be a random variable therefore shoot biomass $w_{s}$ can be represented in the form $w_{s}=\sum_{k=1}^{n_{s}} \beta l_{k}^{\alpha}$. Both models presented similar determination coefficients values of 0.85 and 0.87 respectively. We found no significant differences between parameters $\alpha \quad(p=0.11)$ and $\beta(p=0.50)$ fitted for each model, showing that both equations conduced to the same result. Moreover, both fitted models presented high Concordance Correlation Coefficients of reproducibility $(\hat{\rho})(0.92$ and 0.91). We concluded that for shoot weight assessments if larger samples and faster data processing is required then should model of Equation (2) be used. On the other hand, we proposed model of Equation (1) if data at leaf level is required for other endeavors.
\end{abstract}

Keywords: Allometric Models; Aggregated Data; Leaf Dry Weight; Shoot Dry Weight

\section{Introduction}

Because of the valuable services that Zostera marina meadows provide to shallow coastal ecosystems, [1-6] accurate measurements of biomass or productivity of this eelgrass are important for the study and modeling of such environments. Since shoot biomass is the basic unit to study production in the eelgrass $Z$. marina, many attempts have been made to model biomass in terms of other shoot characteristics as leaf length and width $[7,8]$. On the other hand, shoot biomass assessments for Z. $m a$ rina are reported in a variety of methodologies, some at a leaf level [7-11], and some in aggregated way [12,14]. Although aggregated data are sometimes easy and faster to obtain, measurements cannot be used to fit models and make comparisons with other data sets.

The importance of modeling seagrasses in terms of other variables has been pointed out by several authors [7,9,11,15-17]. One of the main features of modeling is to calibrate non-destructive methods, that is, once the goodness of fit of a particular model is tested to data, the model can be used to predict the pertinent dependent variable from one or several independent variables that

${ }^{*}$ Corresponding author. are obtained in a non-destructively way. In this paper we prove that we can obtain robust allometric parameters even if the data are collected at leaf level or an aggregated form.

\section{Materials and Methods}

\subsection{Data and Related Calculations}

The data used for this study were collected from January to December 2001 in a Z. marina meadow in Punta Banda Estuary, located $23 \mathrm{~km}$. south of Ensenada, Baja California, Mexico at $31^{\circ} 43^{\prime} \mathrm{N}-46^{\prime} \mathrm{N}$ and $116^{\circ} \mathrm{N} 37^{\prime} \mathrm{W}-$ $40^{\prime} \mathrm{W}$. For a detailed description of the site see [10]. Since has been proven that for Zostera marina allometric parameters are time invariant $[8,10,18]$ we believe that a hole year cycle is sufficient to compare the two methods. At each sampling time $t$, using the Kentula and McIntire method [19], approximately 20 shoots were marked biweekly. Only complete leaves were used for the analysis. Since Zostera marina present a ribbon like architecture leaf length was measured from the tip to the ligula [see [20]), width was measure at halfway of the length, this measure of width has been proven to be the best representative proxy of leaf width [20], dry weigh was also 
determined using standard methodology. For this study only leaf length and dry weight were analyzed. Data were then tested at a single leaf bases and in an aggregated form and results were statistically compared. We also calculated the Lin [21] Concorance Correlation Coefficient of reproducibility $(\hat{\rho})$ for predicted and observed values in each fitted model.

\subsection{Formal Methods}

Some authors $([7,8,10,11,15]$ among others), have proven that leaf dry weight can be consistently represented allometrically in terms of leaf length and/or leaf width or area. They considered the allometric basic model

$$
w=\beta l^{\alpha},
$$

were $w$ and $l$ represent the dry weight and length of a single leaf respectively and $\alpha$ and $\beta$ are parameters to be fitted. That means that leaf dry weight can be represented in terms of leaf length.

On the other hand, when individual leaf dry weight is not available and dry weight data is represented in an aggregated form, that is, weight is obtained at a shoot level, we cannot fit Equation (1). Nevertheless, the dry weight of each leaf in a given shoot can be considered to be a random variable and can thus be expressed as several-variables version of the allometric Equation (1) therefore shoot biomass $w_{s}$ can be represented in the form

$$
\begin{aligned}
& w_{s}=\sum_{k=1}^{n_{s}} \beta\left(l_{1}^{\alpha}+l_{2}^{\alpha}+\cdots+l_{n_{s}}^{\alpha}\right) \\
& w_{s}=\sum_{k=1}^{n_{s}} \beta l_{k}^{\alpha},
\end{aligned}
$$

where $l_{k}$ denotes the length of the $k t h$ leaf and $n_{s}$ stands for the number of leaves in the shoot under consideration. Models of Equations (1) and (2) where fitted using standard nonlinear regression methods.

\section{Results}

For the whole annual cycle, we recovered 128 shoots with 393 complete leaves. Table 1 shows basic statistic for leaf length $(l)$, dry weight $(w)$ and shoot dry weight $w_{s}$, showing high variability on all of these variables.

Equation (1) was fitted at leaf level data with a determination coefficient of 0.85 and fitted parameters $\alpha=$ $1.19 \pm 0.045$ and $\beta=0.00002 \pm 0.000008$. Figure 1 shows predicted versus observed values of this fit. Subsequently the Lin [19] Concordance correlation coefficient of reproducibility $(\hat{\rho})$ was performed between observed and predicted values for the fit of Equation (1) finding a value of 0.92. Similarly, for measurements of weights at a shoot level, the several-variable version of Equation (1), (Equation (2)) was fitted using nonlinear
Table 1. basic statistics for leaf length, weight and shoot weight.

\begin{tabular}{ccccc}
\hline & Mean & Min. & Max. & Std. Dev. \\
\hline Length & 188.09 & 4 & 517 & 124.7 \\
Leaf dry weight & 0.015 & 0.0001 & 0.06 & 0.01 \\
Shoot dry weight & 0.046 & 0.005 & 0.39 & 0.03 \\
\hline
\end{tabular}

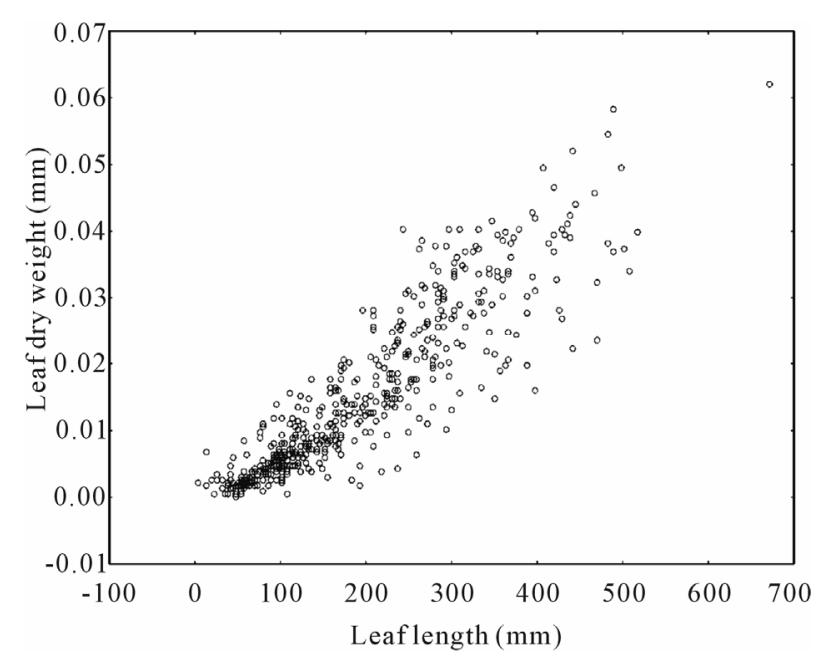

Figure 1. Leaf dry weight in terms of leaf length fitted by Equation (1).

multiple regression finding a determination coefficient $R^{2}=0.87$ and values for $\alpha=1.17 \pm 0.051$ and $\beta=$ $0.00003 \pm 0.000009$. The estimation errors for both fittings were 0.00003 and 0.0002 respectively.

The corresponding plot of predicted versus observed values is shown in Figure 2. The Concordance correlation coefficient of reproduciblity was of $\hat{\rho}=0.91$.

Residuals shown Normality and homoscesticity, although dispersion apparently is bigger for residuals of the fitting of Equation (1) (see Figure 3).

Since Equations (1) and (2) were both fitted using least square method parameters, they are distributed normally therefore we performed a $t$ test between parameters finding no significant differences between parameters with a $p$-value of 0.11 for $\alpha$ and 0.50 for $\beta$. This demonstrates that the fitted parameters in Equations (1) and (2) are statistically the same with a 0.95 confidence level. Moreover, using the Akaike information criterion (AIC) [22] the AIC for Equation (1) is the minimum between both fits with a value of -3660 and the AIC for the fitting of Equation (2) the $\mathrm{AIC}=-1156.35$ therefore since this is less than 4 times the minimum (3.1) we have considerable support to consider it a good model for inference purposes. Moreover using parameters found in Equations (1) and (2) we projected mean shoot weight per month, Figure 4 shows the comparison with observed values. 


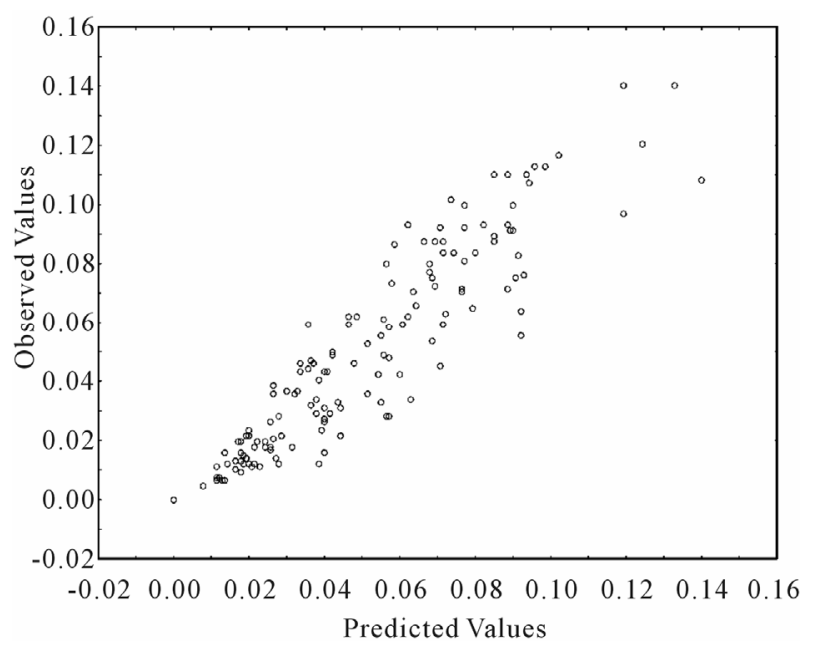

Figure 2. Predicted versus observed values of the fitting of Equation (2) to shoot dry weight in terms lengths of leaves in a shoot.

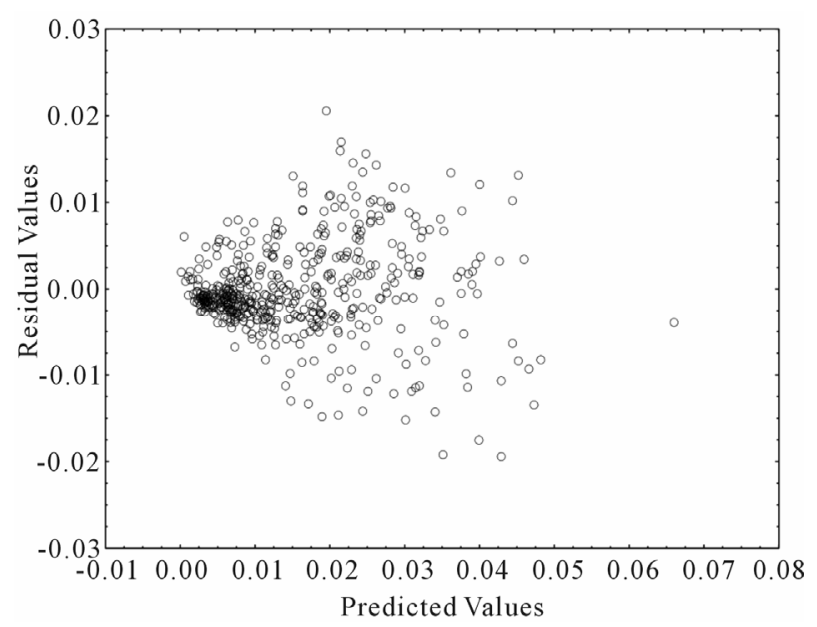

(a)

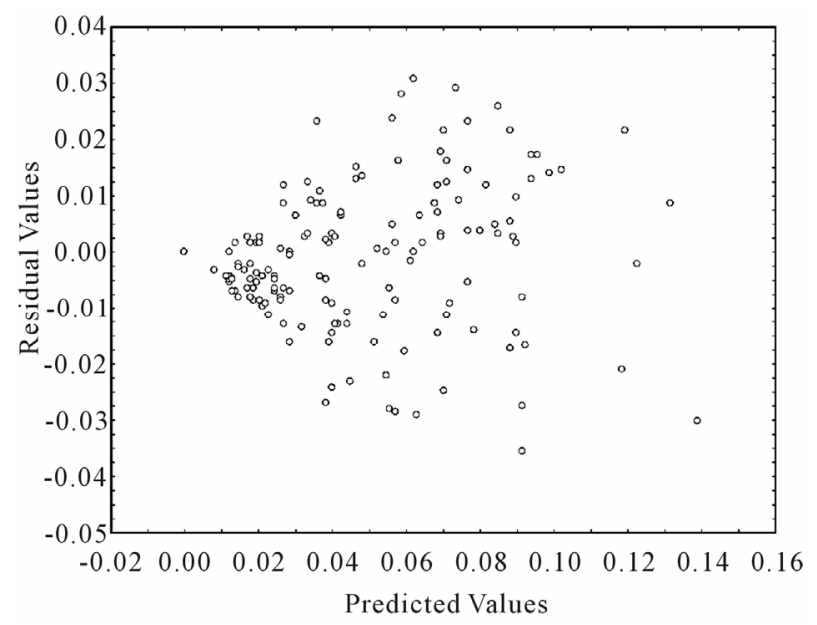

(b)

Figure 3. Distribution of residual of respective fittings (a) allometric Equation (1); (b) Equation (2), which is a multivariate version of Equation (1).

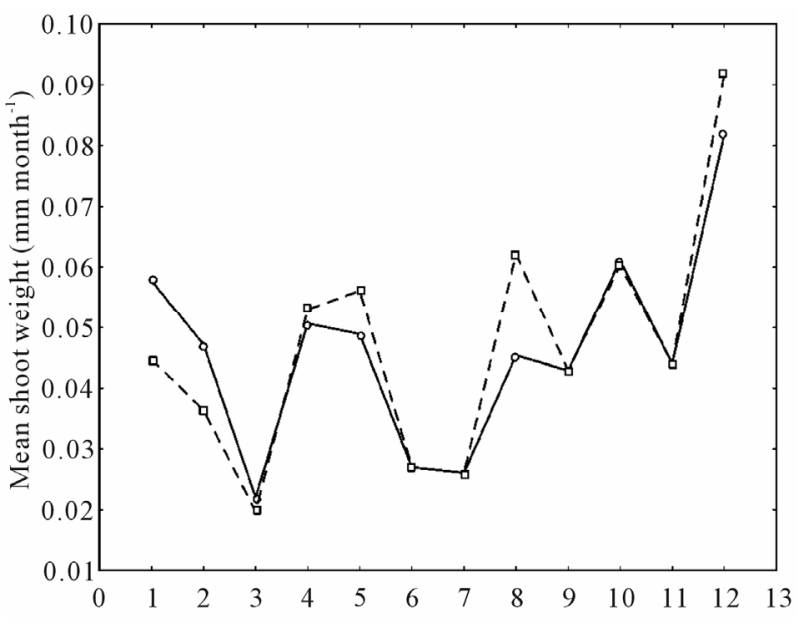

(a)

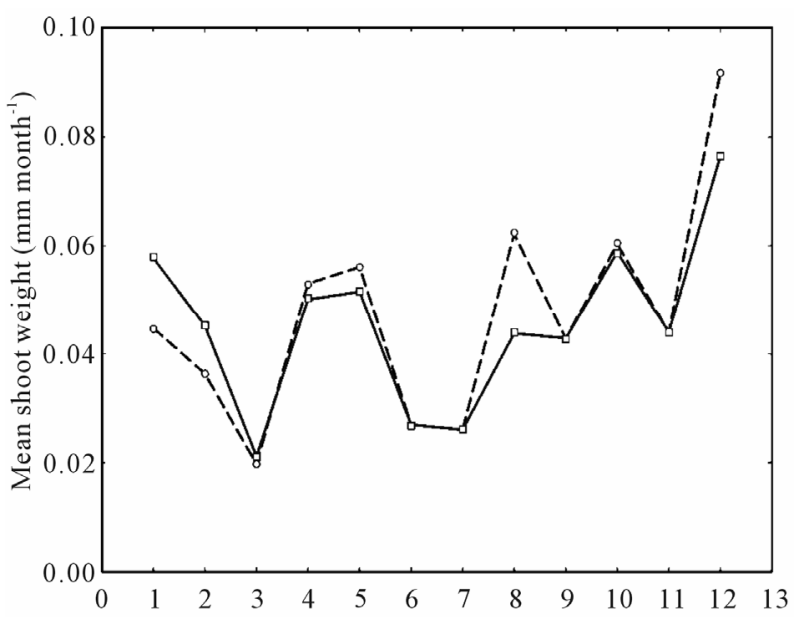

(b)

Figure 4. Observed (dashed lines) and projected (continuous lines) mean shoot weight per month. (a) By means of allometric Equation (1) this is, at a leaf level (b) Using the multivariate Equation (2), this is at a shoot level.

Residuals showed normality and homoscesticity, although dispersion apparently is bigger for residuals of the fitting of Equation (1) (see Figure 3).

\section{Discussion}

Body size affects the structure and functioning at all levels of biological organization from individuals, populations, communities and ecosystems [23]. Related to body size, is the allometry term used first by Huxley (1932 in [23]) to describe the study of the relationship between body size and other variables. The importance of allometric relationships to describe and predict production/ biomass of seagrass communities have been used by several authors [7-11,15]. Moreover, [24] present a complete discussion on how application of allometric laws prediction could benefit our understanding of estuaries and coastal ecology. However, for Z. marina, sampling 
and processing sufficient data to test a robust statistical method, could be an extremely time consuming endeavor. For that reason some authors use aggregated data or data at a shoot level instead of data at a leaf level (non-aggregated) to test differences of some measurements in time and space [13]. Moreover, data gathering for eelgrass assessments methods could be time consuming and destructive. For example at a leaf level, each leaf in a shoot should be counted, measured (length and width) and weighted implying a enormous time of sample processing and for biomass (for example) a bigger error in weighting each leaf separately.

On the other hand, aggregated data, could be easier to obtain and present less error, but could not be used in some models that require individual measurements, as Equation (1).

We have demonstrated in this work, that for biomass assessments a several-variables version of the allometric Equation (1), Equation (2) where leaf dry weights are aggregated at a shoot level gives the same results as the assessments found for the fitting of Equation (1). We found that parameters fitted for both models were statistically the same with $\mathrm{p}=0.11$ for $\alpha$ and $\mathrm{p}=0.50$ for $\beta$. The determination coefficients for both fittings were also statistically the same $(p>0.05)$. Moreover Lin [19] Concordance Correlation Coefficient of reproducibility $(\hat{\rho})$ attained exactly the same value for both fits $(0.92)$, and The AIC shows that both models deserve consideration for statistical inference. Figure 4 shows that projected values of mean shoot biomass per month are almost identical and in a good correspondence with observed values, therefore we consider that Equations (1) and (2) can be used indistinctly for shoot biomass assessments. Nevertheless, the fitting of Equation (1) gives us the advantages of a smaller estimation error, but with the disadvantage of bigger time consuming in data processing. Whereas in the fitting of Equation (2) processing data is much less time consuming but have a slight higher estimation error and a better disposition of residuals. Moreover, since the time of processing material in aggregated form is much less time consuming, bigger samples can be taken if necessary. In any case, regardless of the type of data (aggregated or non-aggregated), the allometric relationship between leaf or shoot dry weight and leaf length is consistent for Zostera marina. In conclusion, for shoot weight assessments, we proposed model of Equation (2) for large samples and faster data processing and model of Equation (1) if data at leaf level is required for other endeavors.

\section{Acknowledgements}

The authors thank Jose Maria Dominguez and Francisco Ponce for the art work.

\section{REFERENCES}

[1] F. T. Short and C. A. Short, "The Seagrass Filter: Purification of Coastal Water," In: V. S. Kennedy, Ed., The Estuary as a Filter, Academic Press, Orlando, 1984, pp. 395-413.

[2] G. W. Thayer, W. J. Kenworthy and M. S. Fonseca, "The Ecology of Eelgrass Meadows of the Atlantic Coast: A Community Profile," US Fish and Wildlife Service Division of Biological Services, FWS/OBS-84/02, No. 147, 1984.

[3] L. G. Ward, W. M. Kemp and W. R. Boynton, "The Influence of Waves and Seagrass Communities on Suspended Particulates in an Estuarine Embayment," Journal of Marine Geology, Vol. 59, No. 1-4, 1984, pp. 85-103. doi:10.1016/0025-3227(84)90089-6

[4] M. S. Fonseca and J. S. Fisher, "A Comparison of Canopy Friction and Sediment Movement between Four Species of Seagrass with Reference to Their Ecology and Restoration," Marine Ecology Progress Series, Vol. 29, 1986, pp. 15-22. doi:10.3354/meps029015

[5] T. P. Williams, J. M. Bubb and J. N. Lester, "Metal Accumulation within Salt Marsh Environment: A Review," Marine Pollution Bulletin, Vol. 28, No. 5, 1994, pp. $277-$ 290. doi:10.1016/0025-326X(94)90152-X

[6] K. L. Heck, K. W. Able, C. T. Roman and M. P. Fahay, "Composition, Abundance, Biomass and Production of Macrofauna in a New England Estuary: Comparison among Eelgrass Meadows and Other Nursery Habitats," Estuaries, Vol. 18, No. 2, 1995, pp. 379-389. doi: $10.2307 / 1352320$

[7] S. P. Hamburg and P. S. Homann, "Utilization of Growth Parameters of Eelgrass, Zostera marina, for Productivity Estimates under Laboratory and in Situ Conditions," Marine Biology, Vol. 93, No. 2, 1986, pp. 299-303. doi:10.1007/BF00508267

[8] E. Solana-Arellano, D. J. Brobon-Gonzalez and H. A. Echavarria-Heras, "A General Allometric Model for Blade Production in Zostera marina L.," Bulletin of Southern California Academy of Sciences, Vol. 97, 1998, pp. 3948.

[9] C. M. Duarte, "Temporal Biomass Variability and Production/Biomass Relationships of Seagrass Communities," Marine Ecology Progress Series, Vol. 51, 1989, pp. 269-276. doi: 10.3354/meps051269

[10] H. Echavarria-Heras, K. S. Lee, E. Solana-Arellano and E. Franco-Vizcaíno, "Formal Analysis and Evaluation of Allometric Methods for Estimating Above-Ground Biomass of Eelgrass," Annals of Applied Biology, Vol. 159, No. 3, 2011, pp. 503-515. doi:10.1111/j.1744-7348.2011.00511.x

[11] E. Solana-Arellano, S. E. Ibarra-Obando and H. A. Echavarria-Heras, "Calibración de un Modelo Alométrico para Evaluar la Producción Foliar de Zostera marina L.," Hidrobiológica, Vol. 1, 1991, pp. 41-44.

[12] K. Aioi, "Seasonal Change in the Standing Crop of Eelgrass Zostera marina L. in Odawa Bay, Central Japan," Aquatic Botany, Vol. 8, 1980, pp. 343-354. doi:10.1016/0304-3770(80)90064-9 
[13] K.-S. Lee, S. R. Park and J.-B. Kim, "Production Dynamics of the Eelgrass, Zostera marina in Two Bay Systems on the South Coast of the Korean Peninsula," Marine Biology, Vol. 147, No. 5, 2005. pp. 1091-1108. doi:10.1007/s00227-005-0011-8

[14] W.-T. Li, J.-H. Kima, J.-I. Parka and K.-S. Lee, “Assessing Establishment Success of Zostera marina Transplants through Measurements of Shoot Morphology and Growth," Estuarine, Coastal and Shelf Science, Vol. 88, No. 3. 2010, pp. 377-384. doi:10.1016/j.ecss.2010.04.017

[15] C. M. Duarte, "Allometric Scaling of Seagrass Form and Productivity," Marine Ecology Progress Series, Vol. 77, 1991, pp. 289-300. doi:10.3354/meps077289

[16] M. E. Solana-Arellano, H. A. Echavarria-Heras and S. E. Ibarra-Obando, "Leaf Size Dynamics for Zostera marina L. in San Quintin Bay, Mexico: A Theoretical Study," Estuarine Coastal and Shelf Sciences, Vol. 44, No. 3, 1997, pp. 351-359. doi:10.1006/ecss.1996.0115

[17] T. M. Greve and D. Krause-Jensen, "Predictive Modelling of Eelgrass (Zostera marina) Depth Limits," Marine Biology, Vol. 146, No. 5, 2005, pp. 849-858. doi:10.1007/s00227-004-1498-0

[18] H. Echavarria-Heras, E. Solana-Arellano and E. FrancoVizcaíno, "An Allometric Method for the Projection of Eelgrass Leaf Biomass Production Rates," Mathematical Biosciences, Vol. 223, No. 1, 2010, pp. 58-65. doi:10.1016/j.mbs.2009.10.008

[19] M. E. Kentula and C. D. McIntire, "The Autoecology and Production Dynamics of Eelgrass (Zostera marina L.) in
Netarts Bay, Oregon," Estuaries, Vol. 9, No. 3, 1986, pp. 188-199. doi: $10.2307 / 1352130$

[20] H. Echavarria-Heras, E. Solana-Arellano, C. Leal-Ramirez and E. Franco-Vizcaíno, "The Length-Times-Width Proxy for Leaf Área of Eelgrass: Criteria for Evaluating the Representativeness of Leaf-Width Measurements," Aquatic Consertation: Marine and Freshwater Ecosystems, Vol. 21, No. 7, 2011, pp. 604-613. doi:10.1002/aqc.1219

[21] L. I.-K. Lin, "A Concordance Correlation Coefficient to Evaluate Reproducibility," Biometrics, Vol. 45, No. 1, 1989, pp. 255-268. doi:10.2307/2532051

[22] H. Akaike, "An New Look at the Statistical Model Identification," IEEE Transactions on Autimatic Control, Vol. 19, No. 6, 1974, pp. 716-723.

http://ieeexplore.ieee.org/xpl/articleDetails.jsp?tp=\&arnu mber $=1100705 \&$ contentType $=$ Journals $+\% 26+$ Magazines \&queryText\%3DAn+New+Look+at+the + Statistical + Mod el+Identification

[23] K. J. Anderson-Teixeira, Van M. Savage, A. P. Allen and J. F. Gillooly, "Allometry and Metabolic Scaling in: Ecology," Encyclopedia of Life Sciences (ELS), John Willey \& Sons Ltd., Chichester, 2009. doi:10.1002/978047001592.a0021222.

[24] L. A. Harris, C. M. Duarte and S. W. Nixon, "Allometric Laws and Prediction in Estuarine and Coastal Ecology," Estuaries and Coasts, Vol. 29, No. 2, 2006, pp. 340-344. doi:10.1007/BF02782002 